\title{
Avaliacão e Melhoria da Experiência de Uso do Sistema de Busca das Bibliotecas de SP
}

\author{
Evaluation and Improvement of the Use Experience \\ of the SP Library Search System
}

Graciela Lopes Tocchetto ${ }^{1}$

Ricardo Couto ${ }^{2}$ 


\section{Resumo}

Este projeto tem por objetivo a avaliação da experiência de uso e proposta de methoria para o sistema integrado de busca das bibliotecas municipais de São Paulo. Esse sistema é uma das primeiras interações entre o usuário e o acervo das bibliotecas municipais. O projeto é dividido em três partes: a fase de pesquisa, a fase de análise de resultados e as propostas de melhorias para o sistema. Os métodos de pesquisa utilizados foram análise heurística, teste de usabilidade, análise de tarefa e mapa de navegação. Depois da pesquisa e levantamento de dados, passa-se a análise de resultados obtidos nos testes. Na última parte são apresentadas as propostas de melhorias que incluem nova arquitetura de informação e interface para o sistema.

Palavras-chave: Usabilidade; experiência do usuário; biblioteca.

\section{Abstract}

This paper aims at assessing the experience and proposal of improvement to the integrated search system of the municipal libraries of São Paulo. This system is one of the first interactions between the user and the collection of the municipal library. The project is divided into three parts: the research phase, the phase of analysis and the last phase of the proposals for improvements to the system. The research methods used were analysis heuristics, usability testing, task analysis and map navigation. After the phase of research and data collection, there is the analysis of results obtained from the tests. In the last part are presented the proposals of improvements including new information architecture and interface to the system.

Keywords: Usability; user experience; library. 


\section{Introdução}

As bibliotecas sempre fizeram parte da rede de economia colaborativa de diversas comunidades e cidades. A possibilidade de compartilhar livros e outras obras de forma gratuita é por si só uma ferramenta de inclusão social.

Atualmente é possível constatar que esses conceitos de colaboração e compartilhamento que compõe a economia colaborativa está se espalhando para diversos produtos e serviços. Compartilha-se carros, casas, ferramentas. Além de serviços de streaming que mostram que não é preciso possuir, pode-se acessar somente o que é de seu interesse.

Nesse contexto, observou-se a abrangência do sistema municipal de bibliotecas da cidade (SMB) de São Paulo como uma oportunidade de estudo. Mais especificamente o sistema de busca de itens no acervo dessa rede de bibliotecas, uma das principais ferramentas de contato com os usuários.

O estudo aqui proposto é o de avaliar a experiência de uso desse sistema de busca e posteriormente propor melhorias na arquitetura da informação e também interface.

\section{Justificativa}

O SMB é composto por 107 bibliotecas que "recebem cerca de quatro milhões de consultas por ano. Atualmente os acervos somam mais de cinco milhões de documentos" (SISTEMA... 2016).

No site da prefeitura é possível pesquisar itens no acervo de todas as bibliotecas que compõem o SMB. A possibilidade de pesquisar documentos em apenas uma plataforma é uma grande vantagem para o usuário. Com acesso a essa informação, ele pode localizar a biblioteca que possui a obra de seu interesse e buscá-la quando quiser.

A análise do sistema de busca integrada do SMB avaliou sua usabilidade levando em conta conceitos de design de interação pois, de acordo com Preece, Rogers e Sharp (2005), "uma preocupação central do design de interação é desenvolver produtos interativos que sejam utilizáveis".

Além de focar na eficiência e produtividade na realização de tarefas, o design de interação está cada vez mais preocupado com a criação de sistemas que sejam agradáveis, interessantes, úteis, motivadores, esteticamente apreciáveis etc. Esses conceitos estão ligados com a experiência que proporcionam ao usuário e como ele sentese na interação com o sistema (PREECE; ROGERS; SHARP, 2005).

O usuário deve ser sempre o foco no desenvolvimento de produtos e serviços. Conhecer esse usuário é essencial para entender suas necessidades e conseguir propor soluções para suas dores da melhor maneira possível. Esse projeto se propôs a conhecer os usuários do sistema integrado do SMB e realizar, junto com eles, a avaliação do atual sistema para assim propor melhorias que sejam relevantes e facilitem o uso do mesmo. 


\section{Metodologia}

O problema estudado no presente trabalho é: quais melhorias em termos de usabilidade podem ser feitas no sistema de busca integrado das bibliotecas municipais de São Paulo para que os usuários encontrem com mais facilidade os itens que desejam? Levando-se em consideração a hipótese de que os usuários têm dificuldades para encontrar alguns itens de seu interesse.

Para verificar a veracidade da hipótese acima proposta, utilizou-se métodos de pesquisa experimental e levantamento de dados com os usuários do sistema de busca. O plano experimental proposto utiliza o preenchimento do UX Canvas para conhecer melhor o serviço em questão, mapa de navegação, análise de tarefas, análise heurística e pesquisa com usuários por meio de entrevistas e teste de usabilidade.

Para determinar os problemas e sugestões de melhoria no sistema decidiu-se utilizar diferentes técnicas de pesquisa, pois, de acordo com Preece, Rogers e Sharp (2005), métodos como "testes com usuários e a avaliação heurística geralmente revelam diferentes problemas de usabilidade".

\subsection{UX Canvas}

O preenchimento do canvas possibilita reunir dados essenciais sobre o negócio ou produto e dos usuários em um só lugar, ao mesmo tempo que aborda muitas das preocupações e ansiedades dos potenciais utilizadores (ZAWADZKI, 2016). Optou-se por usar o UX Canvas (Figura 1) elaborado por Alina Prelicz e Leszek Zawadzki. A análise foi feita pensando no produto já existente e também na versão com as melhorias propostas no decorrer desse projeto.

\section{User Centered Design Canvas}

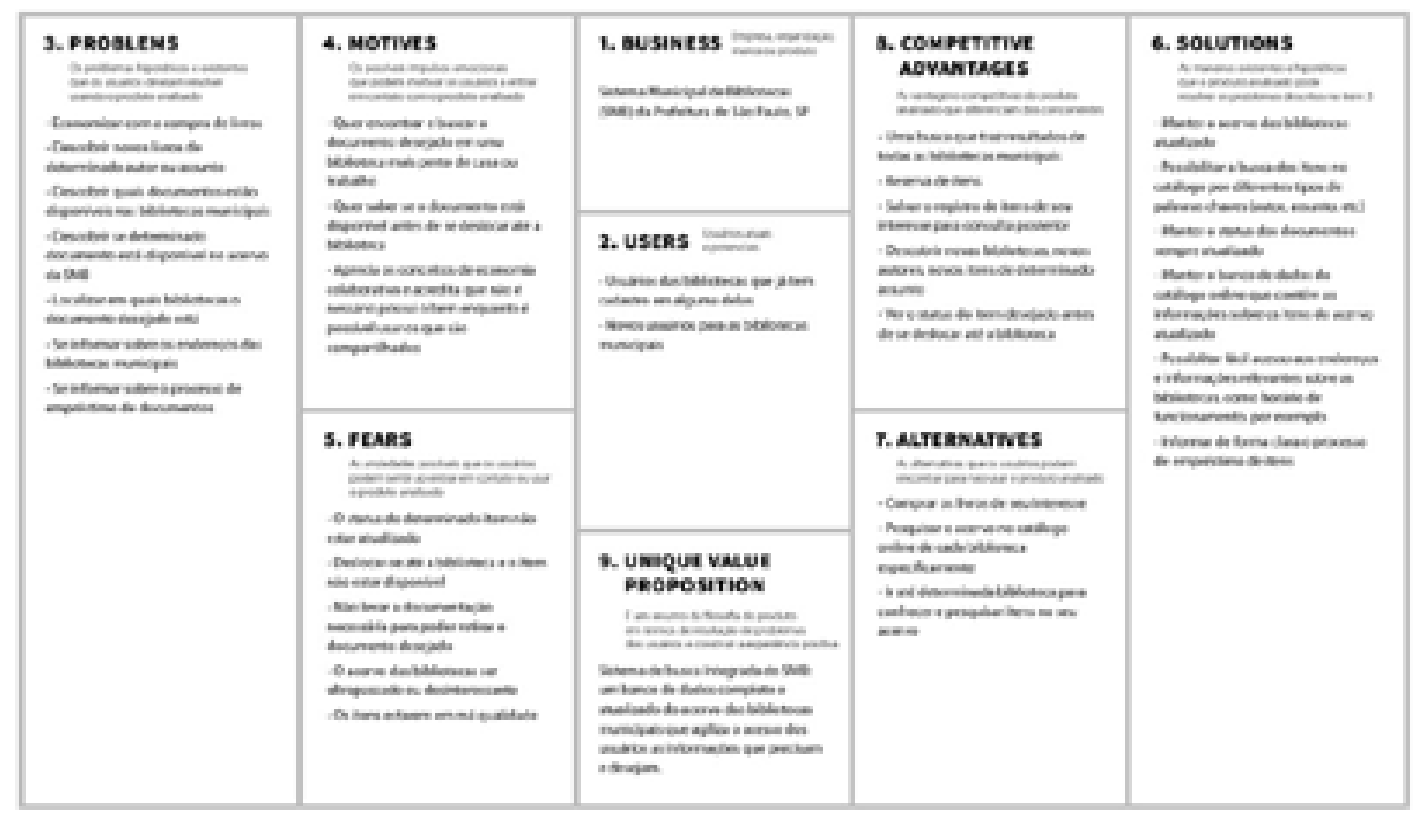




\section{Pesquisa e análise}

\subsection{Mapa de navegação - DoGo Map}

O mapa DoGo é um método ágil. É uma ferramenta que fornece perspectiva sobre o sistema global combinado com a funcionalidade de cada página. Mistura-se a visão de um mapa do site, com o detalhe de um fluxograma para visualizar como um sistema se encaixa. (KEEFER, 2015)

O método consiste em analisar cada página do sistema listando os "input fields" (campos de entrada), as ações possíveis como "do" e os destinos possíveis como "go". Cada página do site ou sistema é numerada e identificada nos itens da lista "go". Além disso, há uma caixa exclusiva para campos comuns em todas as páginas, como no caso de menus (Figura 2). O mapa mistura a visão de mapa do site com o detalhe de um fluxograma o que torna possível visualizar como sistema se encaixa.

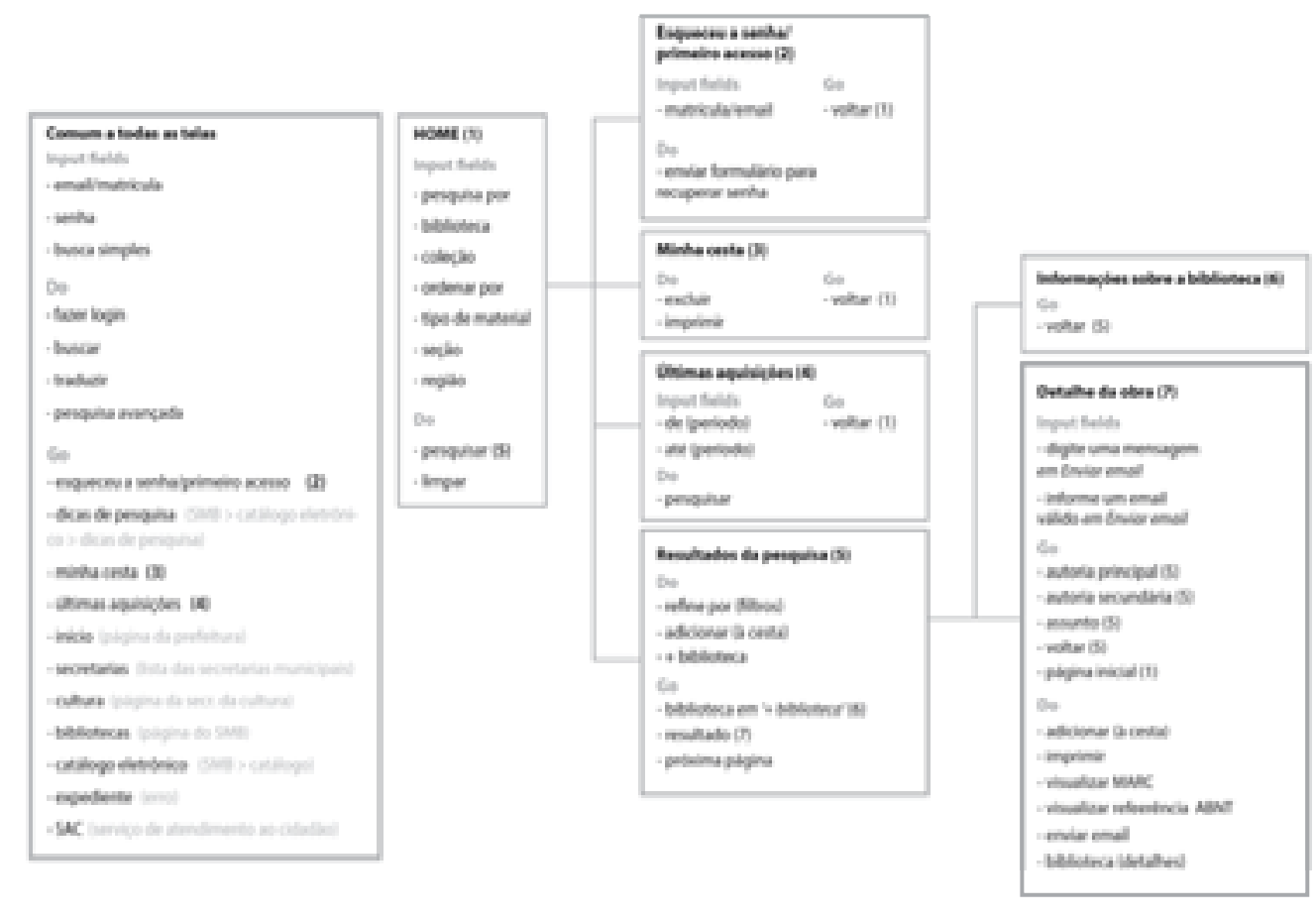

Figura 2: Mapa de navegação do DoGo

\subsection{Análise de tarefa}

A análise de tarefas é um detalhamento das informações e ações necessárias para que o usuário complete uma tarefa. Este documento ajuda designers e desenvolvedores a entenderem o sistema atual e como a informação transita dentro dele. (TEIXEIRA, 2016)

A tarefa analisada (Figura 3) foi encontrar um livro disponível para empréstimo no sistema de buscas do ponto de vista de um usuário que já tenha familiaridade com o uso do mesmo. 


\section{Análise de tarefa}

\section{Encontrar um livro disponivel para empréstimo}



Figura 3: Análise de tarefa

\subsection{Teste de usabilidade com usuários}

O teste de usabilidade é um processo no qual participantes representativos avaliam o grau que um produto se encontra em relação a critérios específicos de usabilidade (RUBIN, 1994).

De acordo com Preece, Rogers e Sharp (2005), o objetivo do teste consiste em responder a uma questão ou hipótese a fim de se descobrir uma informação nova. Além disso, o teste de usabilidade envolve registrar dados utilizando uma combinação de vídeo e registros da interação, questionários de satisfação e também entrevista.

Para a seleção dos usuários, usou-se um formulário que contava brevemente sobre o projeto, questionava o uso da plataforma avaliada e pedia o e-mail de contato de quem se sentisse a vontade de participar do teste. Esse formulário foi publicado em um grupo de leitores e um grupo interessado no mercado editorial no Facebook.

Para esse trabalho, definiu-se o uso da entrevista semiestruturada durante o teste de usabilidade. Trata-se de uma conversa com os usuários que possui questões abertas e fechadas, mesclando características das entrevistas estruturada e não-estruturada (ALCÂNTARA, 2013). Para isso, elaborou-se um roteiro de teste a ser seguido levando em consideração o objetivo da pesquisa. Foram executados 3 testes presenciais e 2 testes de forma remota.

\subsection{Análise heurística}

A avaliação heurística (NIELSEN, 1995) é um método para descobrir os problemas de usabilidade em uma interface. Esse método implica em ter um pequeno conjunto de avaliadores para examinar a interface e julgar sua conformidade com 
princípios de usabilidade já conhecidos, as heurísticas.

Neste projeto, foram convidados 2 avaliadores para colaborar na avaliação heurística da interface da busca integrada das bibliotecas municipais de São Paulo, além da autora deste artigo, somando 3 avaliações.

Meta de avaliação: verificar se a interface atual é consistente e encontrar problemas de usabilidade no sistema.

Para a avaliação heurística foram utilizadas as 10 heurísticas de Nielsen (1995). Para determinar a gravidade dos problemas encontrados também seguiu-se o padrão de Nielsen (1995).

\section{Análise de resultados}

Depois das três análises heurísticas foi possível observar 28 problemas descritos. Destes, quatro são identificados como gravidade 4, nove como 3, doze como 2 e três como gravidade 1.

Os problemas encontrados estão relacionados às seguintes heurísticas: $\mathrm{H} 1$ Visibilidade e feedback: 6 ocorrências; H3 Controle do usuário e liberdade: 1; H4 Consistência e padrões: 4; H5 Prevenção de erros: 3; H6 Reconhecimento em vez de memorização: 4; H7 Flexibilidade e eficiência de uso: 2; H8 Estética e design minimalista: 5; H9 Ajuda aos usuários a reconhecerem, diagnosticarem e recuperarem-se de erros: $1 ; \mathrm{H} 10$ Ajuda e documentação: 2 ocorrências.

Já os problemas de uso encontrados com os testes com usuários foram: a) Não é clara a utilidade do botão "+ Bibliotecas"; b) os participantes não perceberam e/ou não usaram a opção para ordenar os resultados antes de efetuar a busca presente na caixa de pesquisa palavra; c) ao efetuar as tarefas, os participantes perceberam que diversos resultados eram irrelevantes à pesquisa feita; d) nem sempre os autores mais prováveis dos títulos buscados aparecem na opção de filtro; e) alguns usuários relataram que algumas buscas retornam sem resultados quando filtram por biblioteca ou região mesmo quando, segundo elas, essas bibliotecas possuem o livro em questão.

Pontos fortes observados no sistema: todos os participantes conseguiram realizar as tarefas propostas. Não tiveram dúvida sobre como encontrar as informações da biblioteca onde o exemplar estava disponível. Os participantes mais experientes com relação ao mercado editorial filtraram por editora.

Com os testes com usuários e análise heurística foi possível perceber que o sistema de buscas integrado das bibliotecas municipais de São Paulo é eficaz, ou seja, cumpre sua função. Porém, ele deixa a desejar em algumas questões da experiência do usuário como eficiência e maleabilidade, no sentido de permitir que os usuários realizem todas as tarefas da maneira que desejam.

\section{Propostas de melhorias}

Após a fase de pesquisa e análise dos resultados, foi possível perceber diversas oportunidades de melhorias para o sistema. Os pontos principais a serem melhorados observados foram os seguintes: 
- Cabeçalho do site com excesso de informações podendo gerar confusão para os usuários (Figura 4).

- Duplicidade de opção de busca na tela inicial (Busca simples e Busca palavra).

- Busca avançada com opções que são ignoradas pelos usuários. Além de não ficar claro que a "Busca palavra" não é a busca avançada.

- Relevância dos resultados questionável e confusa. A opção para ordenar os resultados aparece antes da busca ser efetuada o que causa dificuldade de uso.

- O botão "+ Bibliotecas" (que aparece nos resultados da busca) não é claro para os usuários, nem todos entendem sua função.

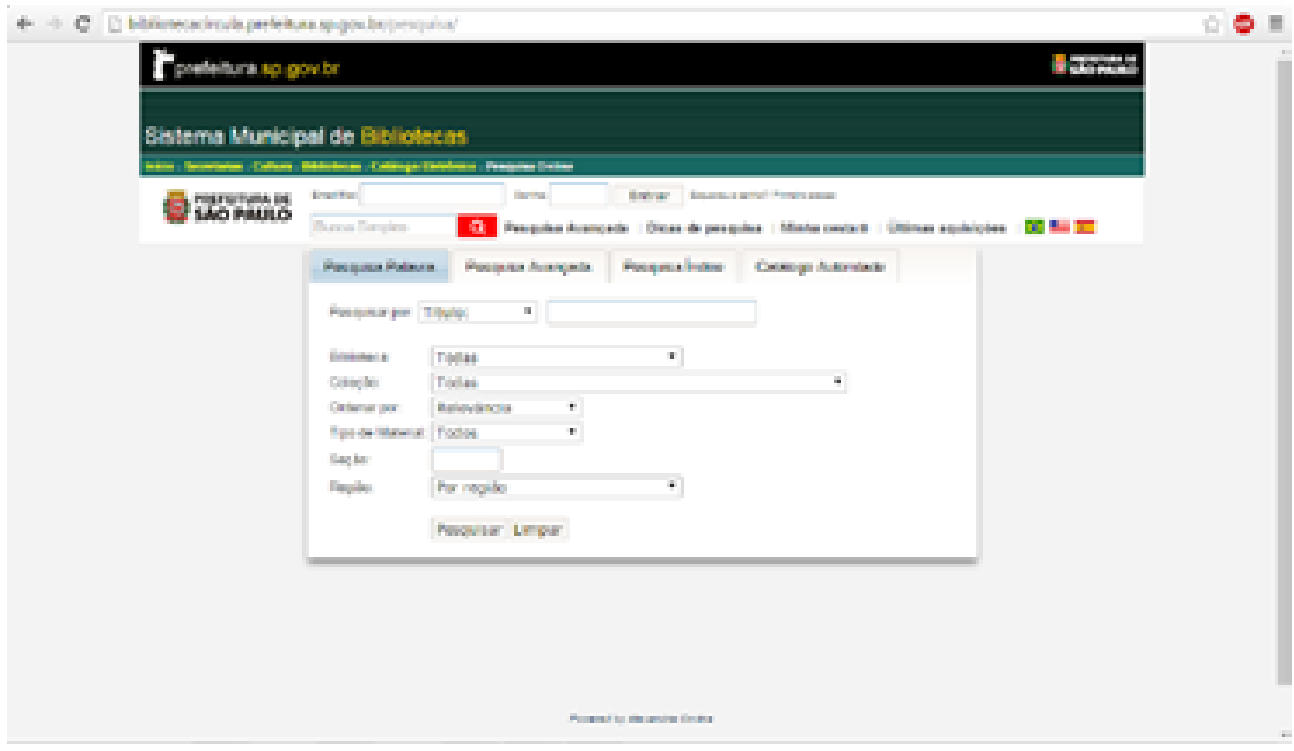

Figura 4: Tela inicial atual

Para a página inicial propõe-se um cabeçalho somente com informações relevantes sobre o sistema de busca (Figura 5). Foco no campo de busca simples com opção para selecionar o tipo de palavra-chave. Campos para login dentro do botão "Login". Marca do SMB aplicada no cabeçalho do site.
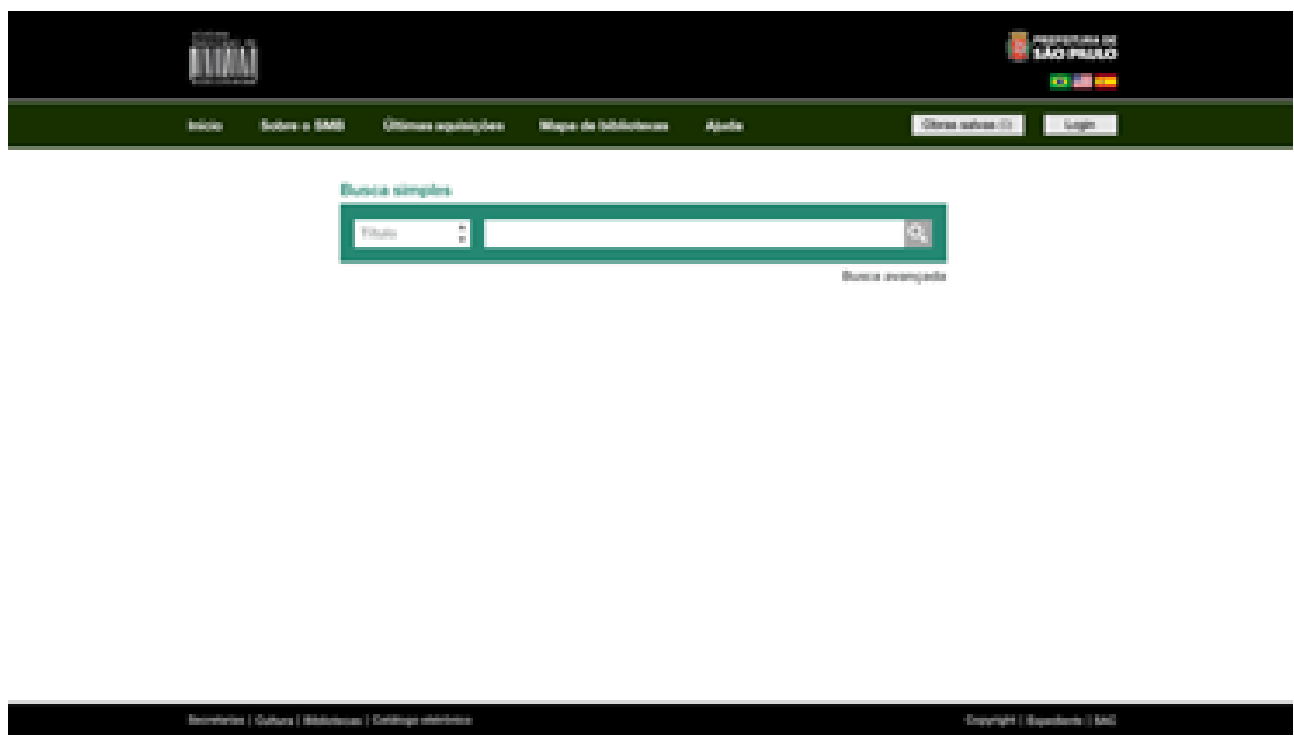

Figura 5: Proposta para tela inicial 
A tela da pesquisa avançada atual (Figura 6) tem informações demais, a maioria ignorada pelos usuários, como vê-se abaixo:

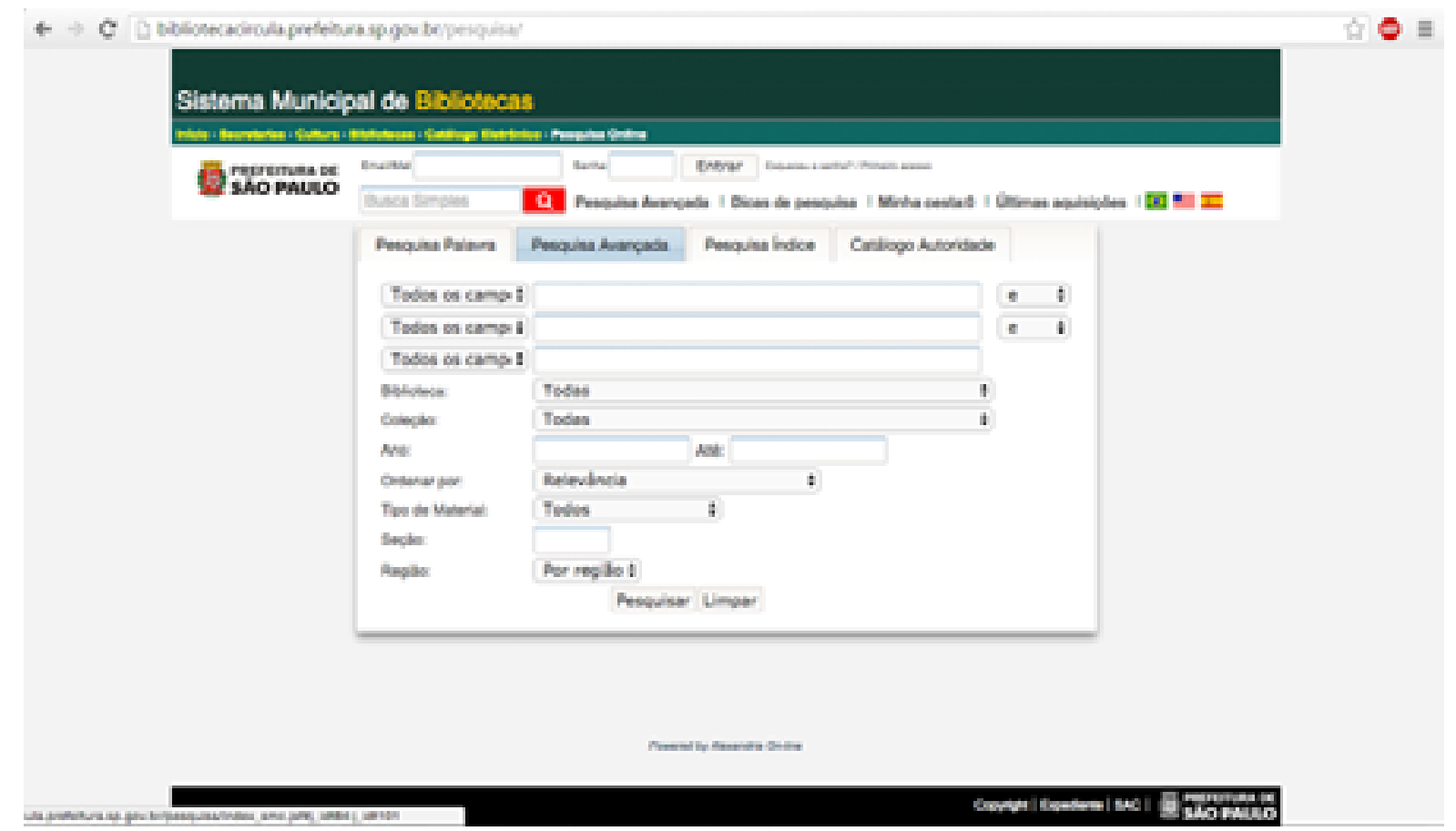

Figura 6: Pesquisa avançada atual

Na proposta para a busca avançada (Figura 7) aparecem os campos de busca com filtro de palavra-chave. Filtro por biblioteca, região, período de publicação e formato. Foram suprimidas as opções em excesso e separados os botões "Limpar" e "Buscar" no intuito de minimizar erros.
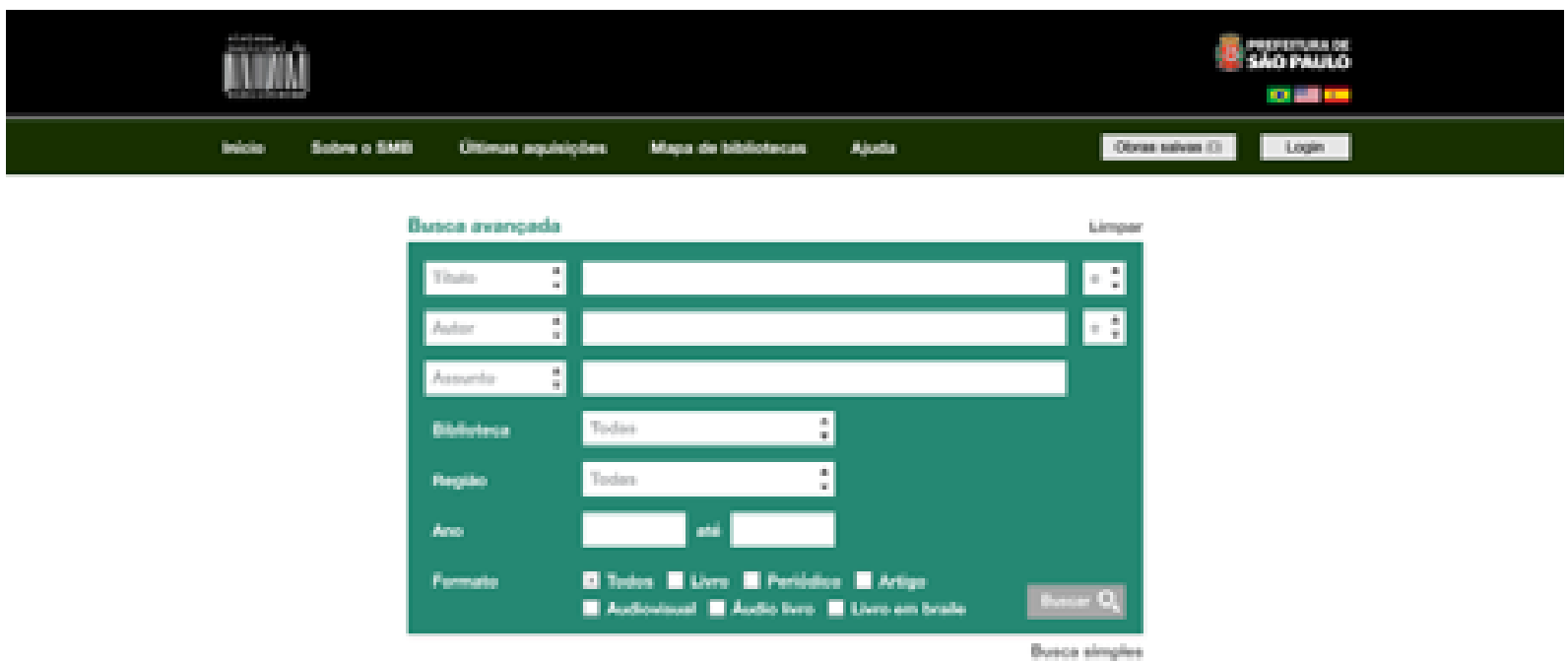
A parte dos resultados da busca (Figura 8) talvez seja a parte mais necessitada de melhorias do sistema. Na interface atual, a seleção do critério da ordem dos resultados deve ser feita antes da busca e somente na opção "Busca avançada", o que foi ignorado por quase todos os usuários durante os testes e análises. Além disso, 0 botão "+ Bibliotecas" apresentou-se pouco efetivo em sua função.

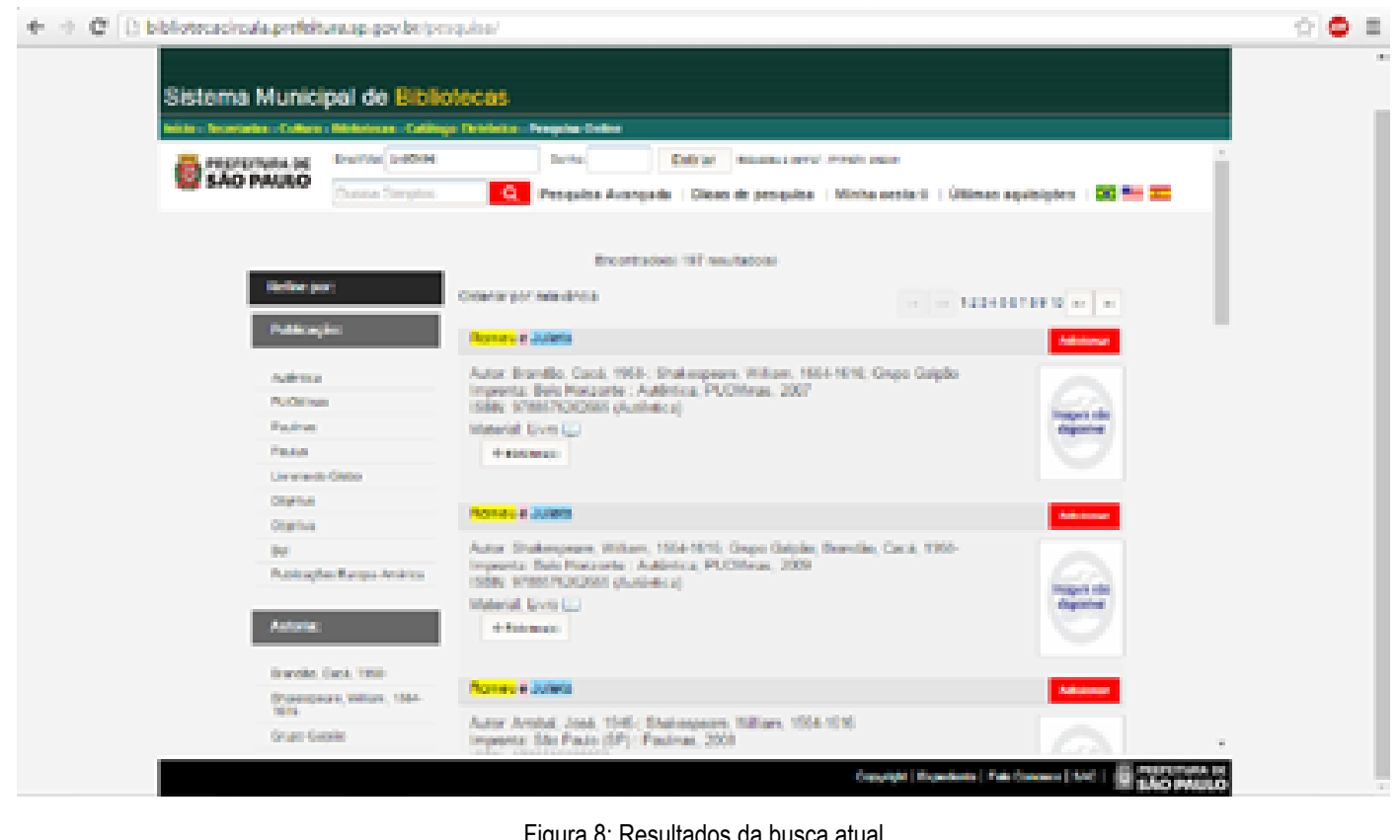

Para a tela com a lista dos resultados (Figura 9) acrescentou-se a possibilidade de reordenar a lista dos resultados. Além disso, propõe-se, do lado esquerdo, um menu com opções para refinar a busca contendo. Também priorizou-se exibir menos informações sobre os exemplares. Outra sugestão foi deixar a última busca realizada preenchida no campo "Busca simples" que fica fixado ao topo (estilo Google).



Figura 9: Proposta de lista dos resultados da busca 
Nessa proposta o botão "+ Bibliotecas" foi substituído por "Disponível na X e mais Y. veja tudo" (Figura 10), por exemplo: "Disponível na Mario de Andrade e mais 6. veja tudo". Ao clicar em "veja tudo" a ideia é que abra um pop-up com a lista das bibliotecas que possuem o exemplar, a localização do item na estante e o status. $O$ status mostra também a quantidade de exemplares em cada biblioteca.
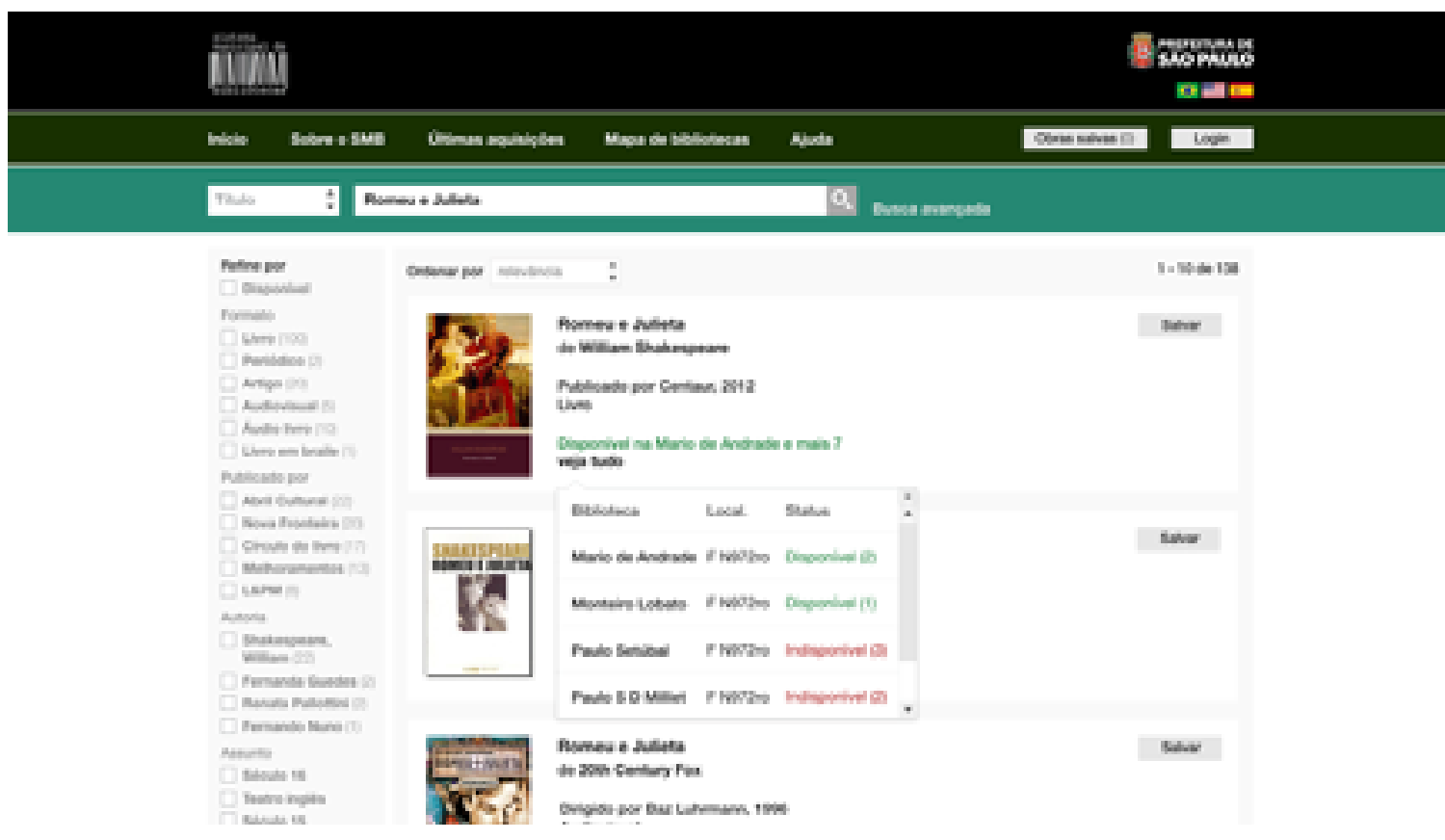

Figura 10: Proposta de lista dos resultados - botão "veja tudo"

Ainda no pop-up "veja tudo", ao clicar no nome da biblioteca, abre-se um pequeno mapa (Google Maps). A ideia é permitir que o usuário consiga relacionar a biblioteca ao endereço de forma mais rápida (Figura 11).



Figura 11: Proposta de lista dos resultados - botão "veja tudo" - mapa 
O protótipo navegável pode ser acessado em: http://adobe.ly/2eeVnRR com todas as telas propostas no projeto.

\section{Considerações finais}

Acredita-se que os objetivos inicialmente propostos no desenvolvimento do projeto foram atingidos de maneira eficaz. Pode-se afirmar que a plataforma de busca do catálogo integrado das bibliotecas que fazem parte do SMB de São Paulo, apesar de cumprir sua função, tem grande potencial para melhoria em termos de experiência do usuário e usabilidade. Chegou-se a essa conclusão com o uso de diferentes métodos e análises aqui apresentados.

Por fim, acreditamos na valorização da biblioteca como espaço público de aprendizado, descobertas e desenvolvimento pessoal e coletivo. Com este trabalho, acreditamos que pudemos dar uma pequena contribuição à sociedade através de métodos e técnicas de design e IHC que poderão melhorar a experiência de consulta ao acervo do sistema municipal de bibliotecas de São Paulo.

\section{REFERÊNCIAS}

ALCÂNTARA, Priscila. Entrevistas. 2013. Disponível em: http://www.slideshare. net/prixvedder/entrevistas-23747564. Acesso em: 13 set. 2016.

KEEFER, Rob. Adapting Information Architecture for Lean and Agile Environments with DoGo Mapping. 2015. Disponível em: http://uxmag.com/articles/adapting-information-architecture-for-lean-and-agile-environments-with-dogo-mapping. Acesso em: 31 ago. 2016.

NIELSEN, Jakob. 10 Usability Heuristics for User Interface Design. 1995. Disponível em: https://www.nngroup.com/articles/ten-usability-heuristics/. Acesso em: 23 ago. 2016.

NIELSEN, Jakob. How to Conduct a Heuristic Evaluation. 1995. Disponível em: https://www.nngroup.com/articles/how-to-conduct-a-heuristic-evaluation/. Acesso em: 26 ago. 2016.

NIELSEN, Jakob. Severity Ratings for Usability Problems. 1995. Disponível em: https://www.nngroup.com/articles/how-to-rate-the-severity-of-usability-problems/. Acesso em: 26 ago. 2016.

PREECE, Jennifer; ROGERS, Yvone; SHARP, Helen. Design de Interação: Além da integração homem-computador. Porto Alegre: Bookman, 2005. 548 p. Tradução de: Viviane Possamai. 
RUBIN, Jeffrey. Handbook of Usability Testing: How to Plan, Design and Conduct Effective Tests. New York: John Wiley \& Sons, Inc., 1994. 330 p.

SISTEMA MUNICIPAL DE BIBLIOTECAS: Quem somos em SMB. 2016. Disponível em: www.prefeitura.sp.gov.br/cidade/secretarias/cultura/bibliotecas/smb/index. php. Acesso em: 13 ago. 2016.

TEIXEIRA, Fabricio. Métodos e entregáveis de UX. Disponível em: http://fabricio. nu/metodos/. Acesso em: 11 out. 2016.

UNGER, Russ; CHANDLER, Carolyn. O guia para projetar UX: A experiência do usuário (UX) para projetistas de conteúdo digital, aplicações e web sites. Rio de Janeiro: Alta Books, 2009. 268 p.

ZAWADZKI, Leszek. Introducing the User-Centered Design Canvas. 2016. Disponível em: https://uxmag.com/articles/introducing-the-user-centered-design-canvas. Acesso em: 14 ago. 2016. 